\title{
Design and Analysis of 2D Photonic Crystal Based Biosensor to Detect Different Blood Components
}

\author{
Rajendran ARUNKUMAR*, Thinakaran SUAGANYA, and Savarimuthu ROBINSON \\ Department of Electronics and Communication Engineering, Mount Zion College of Engineering and Technology, \\ Pudukkottai-622507, Tamil Nadu, India \\ *Corresponding author: Rajendran ARUNKUMAR $\quad$ E-mail: arunec002@gmail.com
}

\begin{abstract}
In this paper, a photonic crystal ring resonator based bio sensor is designed to sense different blood constituents in blood in the wavelength range of $1530 \mathrm{~nm}-1615 \mathrm{~nm}$ for biomedical applications. The blood constituents such as hemoglobin white blood cell, red blood cell, blood sugar, blood urea, albumin, serum bilirubin direct, and ammonia are sensed for the corresponding transmission output power, $Q$ factor, and refractive index changes. As the blood constituent has unique refractive index, the resonant wavelength and output power are varied from one to another, which are used to identify the blood constituents.
\end{abstract}

Keywords: Photonic crystal; plane wave expansion (PWE); finite difference time domain (FDTD); biosensor; blood components

Citation: Rajendran ARUNKUMAR, Thinakaran SUAGANYA, and Savarimuthu ROBINSON, "Design and Analysis of 2D Photonic Crystal Based BIO Sensor to Detect Different Blood Components," Photonic Sensors, 2019, 9(1): 69-77.

\section{Introduction}

In recent years, several diseases are reported from season to season across the world. It can be identified and rectified by analyzing blood components in a patient $[1,2]$. Blood analysis plays a keen role for the detection and prevention of hematological disorders which cause many non-communicable diseases naming cardiovasalar disease, cancer, diabete, respiratory disease, and many unnoticeable diseases which bring 50 million deaths every year worldwide [3-7].

Blood is a body fluid for human which is composed of blood cells suspended in blood plasma about 55\%. It also contains proteins, glucose, mineral ions, hormones, albumin, red blood cells, white blood cells, and platelets $[8,9]$. The physical, chemical, and biological properties of the blood constituents are varied from person to person and disease to disease. Hence, the dielectric value of blood constituents is unique which is highly useful to identify the diseases for various medical applications [10-12]. The name of the blood components, normal range, and its health issues are reported in Table 1.

The conventional blood analysis is a laboratory analysis taking a blood sample from human body. For majority tests, blood is usually obtained from a patient's vein. There are several methods available to analyze the blood components by using methods such as flame atomic absorption spectrometry, graphite furnace atomic absorption spectrometry, laboratory anodic stripping voltammetry (ASV), portable ASV, and inductively coupled plasma mass spectrometry $[13,14]$. The time to analyze the blood is about $24-72$ hours. It also requires more blood samples for detection.

Received: 5 November 2017 / Revised: 25 August 2018

(C) The Author(s) 2018. This article is published with open access at Springerlink.com

DOI: $10.1007 / \mathrm{s} 13320-018-0479-8$

Article type: Regular 
Table 1 Names of the blood components, normal range, and health issues.

\begin{tabular}{|c|c|c|}
\hline $\begin{array}{l}\text { Name of the blood } \\
\text { components }\end{array}$ & Normal range & Health issues \\
\hline Hemoglobin & $\begin{array}{c}\text { Male }: 13.5 \mathrm{gms} / \mathrm{dl}- \\
17.0 \mathrm{gms} / \mathrm{dl} \\
\text { Female }: 12.5 \mathrm{gms} / \mathrm{dl}- \\
15.5 \mathrm{gms} / \mathrm{dl}\end{array}$ & $\begin{array}{l}>\text { Lung disease, cancer } \\
<\text { anemia }\end{array}$ \\
\hline White blood cell & $\begin{array}{l}4500 \text { Cells/cumm-- } \\
11000 \text { Cells/cumm }\end{array}$ & $\begin{array}{l}>\text { Leukemia } \\
<\text { infection }\end{array}$ \\
\hline Red blood cell & $\begin{array}{c}\text { Male: } 4.5 \text { Million } \\
\text { cells/cumm-6.0 Million } \\
\text { cells/cumm }\end{array}$ & $\begin{array}{l}>\text { Heart diseases } \\
<\text { anemia }\end{array}$ \\
\hline Blood sugar & $80 \mathrm{mg} / \mathrm{dl}-110 \mathrm{mg} / \mathrm{dl}$ & $>$ Diabetes \\
\hline Blood urea & $20 \mathrm{mg} / \mathrm{dl}-40 \mathrm{mg} / \mathrm{dl}$ & $\begin{array}{l}>\text { Heart diseases } \\
<\text { kidney diseases }\end{array}$ \\
\hline Albumin & $3.4 \mathrm{gms} / \mathrm{dl}-5.4 \mathrm{gms} / \mathrm{dl}$ & $\begin{array}{c}>\text { Kidney diseases } \\
<\text { liver diseases like } \\
\text { hepatitis }\end{array}$ \\
\hline $\begin{array}{l}\text { Serum bilirubin } \\
\text { direct }\end{array}$ & $\begin{array}{l}0.3 \mathrm{mg} / \mathrm{dl}-1.0 \mathrm{mg} / \mathrm{dl} \\
\text { Child : up to } 11.0\end{array}$ & $\begin{array}{c}>\text { Jaundice, liver cancer } \\
<\text { no issues }\end{array}$ \\
\hline $\begin{array}{l}\text { Serum bilirubin } \\
\text { direct }\end{array}$ & $\begin{array}{l}0 \mathrm{mg} / \mathrm{dl}-0.3 \mathrm{mg} / \mathrm{dl} \\
\text { Child : up to } 0.25\end{array}$ & $\begin{array}{c}>\text { Jaundice, liver cancer } \\
<\text { no issues }\end{array}$ \\
\hline Ammonia & $10 \mathrm{mmol} / \mathrm{L}-47 \mathrm{mmol} / \mathrm{L}$ & $\begin{array}{c}>\text { Cirrhosis, severe } \\
\text { hepatitis } \\
<\text { high blood pressure }\end{array}$ \\
\hline $\begin{array}{c}\text { Alkaline } \\
\text { phosphatase }\end{array}$ & $350 \mathrm{IU} / \mathrm{L}-570 \mathrm{IU} / \mathrm{L}$ & $\begin{array}{l}\text { > Bone cancer, liver } \\
\text { cancer, heart failure } \\
<\text { celiac disease (or) } \\
\text { deficiency in vitamins } \\
\text { and minerals }\end{array}$ \\
\hline
\end{tabular}

Alternatively, the optical bio-sensing method is employed for blood analysis which gives results with lesser time and a very small amount of blood samples are sufficient for detection. There are two methods available for blood analysis such as florescence based detection method and label free detection method. As the quantitative analysis of blood is very difficult in florescence based detection, the label free detection method is employed vibrantly. In the label free detection method, the blood analysis is carried out by knowing the value of refractive index of the target sample [14, 15].

The photonic sensing technology using photonic crystal (PC) enables the new measurement possibility for blood constituent analysis. As the permittivity of the biological molecules is greater than those of air and water, the propagation of electromagnetic waves is varied while passing through the structure. Owing to the aforementioned process, the analytes are easily identified and detected, which can be further used for medical applications [16]. PCs are periodic nanostructures that affect the motion of photons in the same way as the periodic potential in a semiconductor crystal affects the electron motion by defining allowed and forbidden electronic energy bands. In general, PCs are composed of periodic dielectric and metallodielectric nanostructures which have alternative lower and higher dielectric constant materials in one, two, and/or three dimensions to affect the propagation of electromagnetic waves inside the structure. As a result of this periodicity, the transmission of light is absolutely zero in certain frequency ranges, which is called photonic band gap (PBG) $[17,18]$. By introducing defects in these periodic structures, the periodicity and thus the completeness of the PBG are entirely broken, which allows to control and manipulate the light. Two dimensional photonic crystals (2DPC) are receiving much attention from the research and scientific community in designing the optical devices as they have attractive features including better confinement of light, efficient PBG calculation, effective control of spontaneous emission, relatively simple fabrication than 3DPCs, and easy integration with other devices [18]. 2DPC based optical devices, such as optical sensors [19], filters [20], multiplexers, de-multiplexers, directional couplers, power dividers/splitters, logic gates, and switches [21], have already been reported.

Typically, two sensing schemes are reported in the photonic sensing technology, namely, the resonant wavelength shift scheme and the intensity reduction scheme. In the first scheme, the resonant wavelength shift is noticed for different values of analytes. Alternatively, the intensity is reduced while varying the dielectric parameters of the analytes [22-26]. There are several methods reported to sense the refractive index change of various biosensors, namely brass grating, Mach-Zehnder interferometer, and micro ring resonator [23, 24]. The micro ring resonator offers highly desirable results as it provides higher sensitivity and higher output power. However, the bending loss and radiation loss are very high that the radius of the ring resonator is less than $5 \mu \mathrm{m}$ which can be reduced through a photonic 
crystal ring resonator [27-34].

In present work, a photonic crystal ring resonator (PCRR) based sensor has been designed and simulated for detection of different blood components, namely, urethame dimethacrylate, bovine serum albumin, polyacrylamide, biotin-streptavidin, sylgard184, glucose $(40 \mathrm{gm} /$ $100 \mathrm{ml}$ ), hemoglobin, ethanol, blood pPlasma, cypton, and water, and the effect of sensor parameters are also investigated. In the remaining parts of this paper, Section 2 represents the numerical analysis of the proposed sensor. Section 3 represents the design of $\mathrm{PC}$ ring resonator based biosensor of the proposed sensor. The simulation results and its significance are presented in Section 4. Section 5 draws conclusions.

\section{Numerical analysis}

Usually, the photonic crystals exhibit property called photonic band gap (PBG). Whether photons propagate through the structure or not depends on the wavelength. Disallowed bands of wavelengths are called PBG. There are many methods, such as transfer matrix method (TMM) [35], finite difference time domain (FDTD) method [36], plane wave expansion (PWE) method [37], and finite element method (FEM) [38], are available to analyze the dispersion behavior and transmission spectra of PCs. Each method has its own pros and cons. Among these, PWE and FDTD methods are dominant with respect to their performance, and they also meet the demand to analyze the PC based devices. The PWE method is initially used for theoretical analysis of PC structures, which makes use of the fact that eigen modes in periodic structures can be expressed as a superposition of a set of plane waves. Although this method can obtain an accurate solution for the dispersion properties (propagation modes and band gap) of a PC structure, it has still some a limitation that transmission spectra, field distribution, and back reflections cannot be extracted because it considers only propagating modes. An alternative approach which has been widely adopted to calculate both transmission spectra and field distribution is based on numerical solutions of Maxwell's equations by using the FDTD method. In this analysis, the PWE is used to calculate the band gap and propagation modes of the PC structure whereas 2DFDTD is used to calculate the spectrum of the power transmission [39].

Since the transmission of electromagnetic waves in certain range of frequencies is prohibited, there is no propagation of light over some order of wavelength [40]. The light propagation can be manipulated by the defect mechanism. The line defect in the ring resonator acts as a waveguide. To increase the sensitivity of the $\mathrm{PC}$, the ring resonator is utilized here. In the ring resonator, the resonant wavelength and the output power can be altered whenever the refractive index of the sample gets varied. The PC functions as sensor can be proved by solving Maxwell's electromagnetic equation.

$$
\nabla \times\left(\frac{1}{\varepsilon} \nabla \times \mathbf{H}\right)=\left(\frac{\omega}{c}\right)^{2} \mathbf{H}
$$

where $\mathbf{H}$ is the magnetic field and $C$ is the speed of light. Also $\varepsilon$ is the permittivity (dielectric function $\varepsilon=\eta^{2}$ or $\eta=\sqrt{ } \varepsilon$ where $\eta$ is the refractive index) and $\omega$ is the frequency of resonance. It is observed that when the dielectric function changes, the frequency also changes. From (1), it is noticed that the dielectric function $\varepsilon$ is inversely proportional to frequency $\omega[41,42]$. The sensing performances of the structure can be analyzed by

$$
L_{\text {eff }}=Q \lambda /(2 \pi \eta)
$$

where $L_{\text {eff }}$ is the effective interaction length, $Q$ is the resonator quality factor, $\lambda$ is the resonant wavelength, and $\eta$ is the refractive index of ring resonator [43].

\section{Design of PC ring resonator based biosensor}

The designed PC based biosensor consists of the cubic array of circular rod placed in a background of air which is shown in Fig. 1. In the cubic lattice, numbers of rods in $X$ and $Z$ directions are 21 and 17, respectively. The radius of the rod is $100 \mathrm{~nm}$, where 
the distance between the adjacent two rods is $540 \mathrm{~nm}$, which is also called as lattice constant denoted by " $a$ ". The dielectric constant of circular silicon rod is 11.97 (refractive index $n=3.46$ ) of the structure. The sensor has an elliptical shape of resonator which is placed in the middle of the structure, and the circular rod front and back radius is $100 \mathrm{~nm}$. The sensor contains two ports, namely, input and output ports, which are used to propagate and analyze the optical signal with different wavelengths.

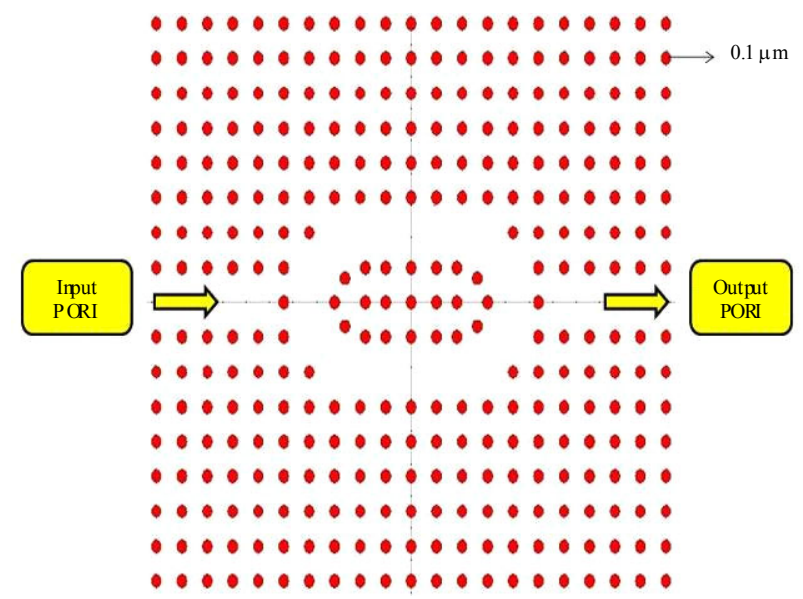

Fig. 1 Proposed biosensor using elliptical ring resonator.

The plane wave expansion method is used to find the PBG of this proposed structure. The propagation mode and PBG of the proposed structure are shown in Fig. 2(a). The normalized frequency of the PC structure is $\omega a / 2 \pi c=a / \lambda$, where $\omega$ is the angular frequency, $a$ is the lattice constant, $c$ is the velocity of light in free space, and $\lambda$ is the free space wavelength. The band diagram has a PBG of two TE modes at different wavelength ranges, which are $1200 \mathrm{~nm}$ to $1800 \mathrm{~nm}$ and $814 \mathrm{~nm}$ to $748 \mathrm{~nm}$. The PBG ranging from $1200 \mathrm{~nm}$ to $1800 \mathrm{~nm}$ is appropriate to the third window, and it is accounted for this attempt.

Figure 2(b) depicts the band diagram of the proposed elliptical ring resonator after introducing the line and point defects. The guided mode shows that there is a propagation mode inside the PBG region owing to incorporation of elliptical shape ring resonator in the periodic structure. The sensor is designed through line and point defects. The 3D view of proposed PC based sensor is shown in Fig. 3, which gives the overall size of $11.4 \mu \mathrm{m} \times 9.2 \mu \mathrm{m}$.

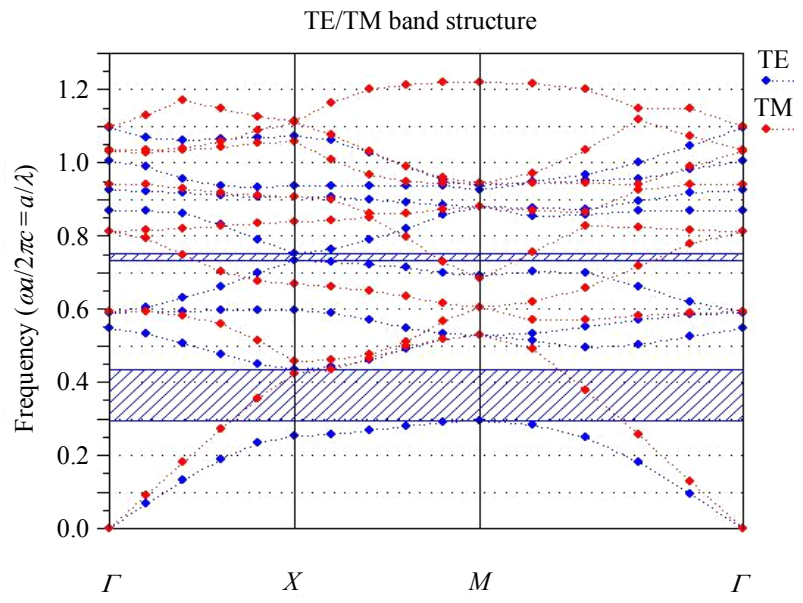

(a)

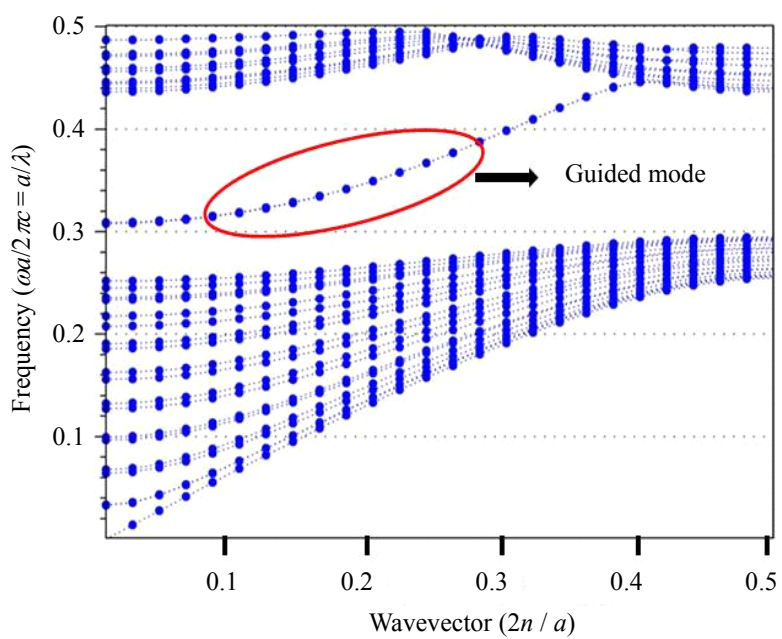

(b)

Fig. 2 Band diagram for circular rods in $21 \times 17$ square lattice: (a) without any defects and (b) with line and point defects.

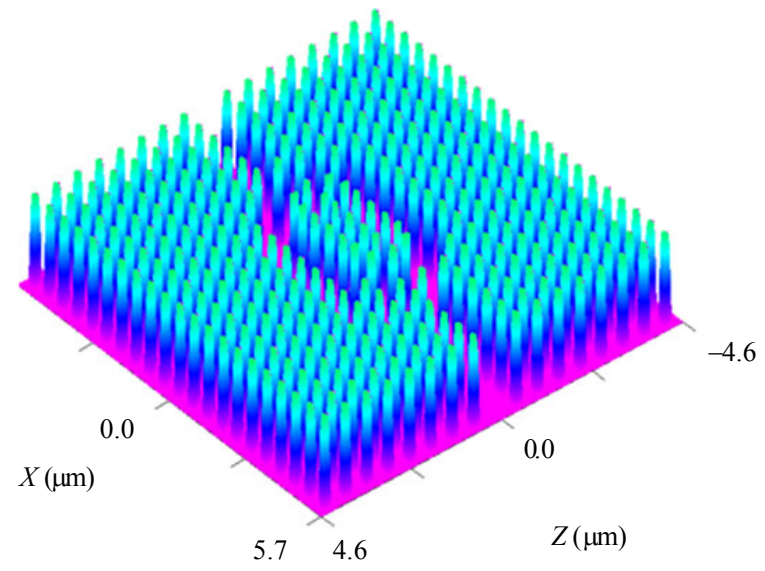

Fig. 3 3D structure of biosensor. 


\section{Simulation results and discussion}

When light signal propagates into the waveguide and passes the elliptical shape of resonator, the output signal power is measured from the power monitor positioned at the output port of the sensor. The obtained output response is used to analyze the resonant wavelength, quality factor, and output power. The normalized transmission spectrum of the sensor is shown in Fig. 4. The resonant wavelength, $Q$ factor, and output efficiency of the sensor at normal condition is $1590 \mathrm{~nm}, 257.5$, and $100 \%$, respectively.

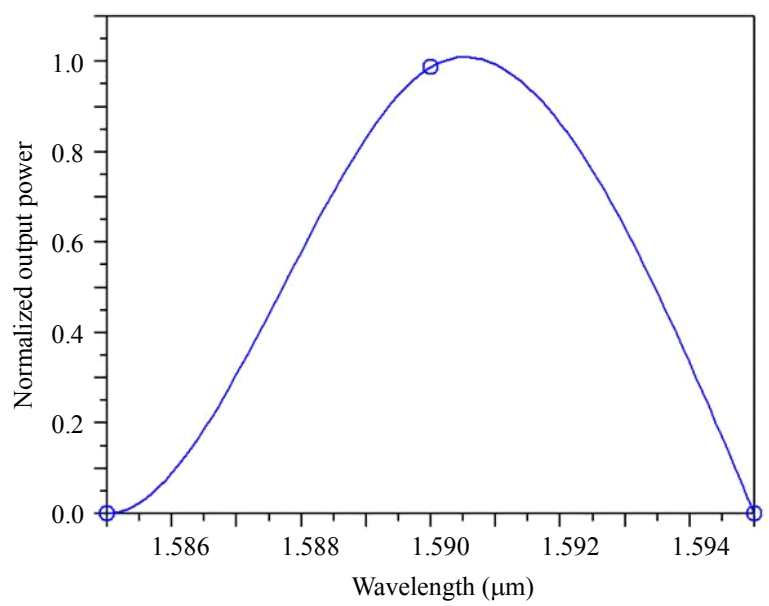

Fig. 4 Normalized transmission spectrum of the proposed biosensor at normal condition.

Figures 5(a) and 5(b) depict the electric field distribution of the proposed sensor at $\mathrm{ON}$ resonance and OFF resonance, respectively. At $1590 \mathrm{~nm}$ i.e. $\mathrm{ON}$ resonance, the input signal is coupled from input waveguide to elliptical resonator which in turn outputs waveguide. Alternatively, the input signal is reflected back to the source at the OFF resonance at $1600 \mathrm{~nm}$.

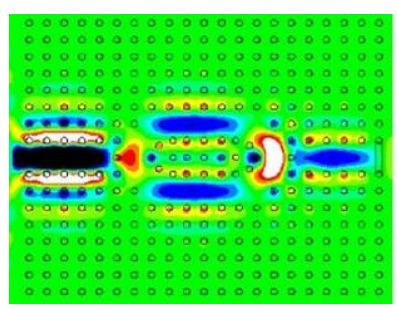

(a)

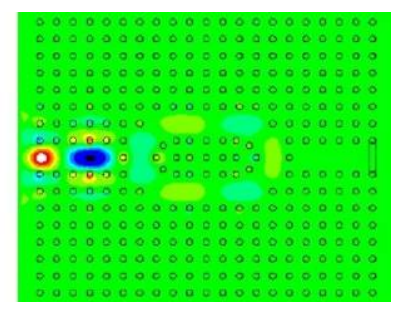

(b)
Fig. 5 Field distribution of the proposed bio sensor at (a) $\mathrm{ON}$ resonance $(\lambda=1590 \mathrm{~nm})$ and (b) OFF resonance $(\lambda=1600 \mathrm{~nm})$.
The normalized output spectra of the sensor for different blood components [26-30] are shown in Fig. 6. The transmission spectra are obtained for various biological constituents present in the blood using the output from the FDTD method [31, 32]. The changes in the normalized output transmission spectra and resonant wavelengths have been analyzed according to the change in the dielectric constant of different bio-constituents present in blood. Table 2 shows input dielectric constant $\left(\varepsilon_{r}\right)$, normalized transmission power, and resonant wavelength for different blood components present in blood.

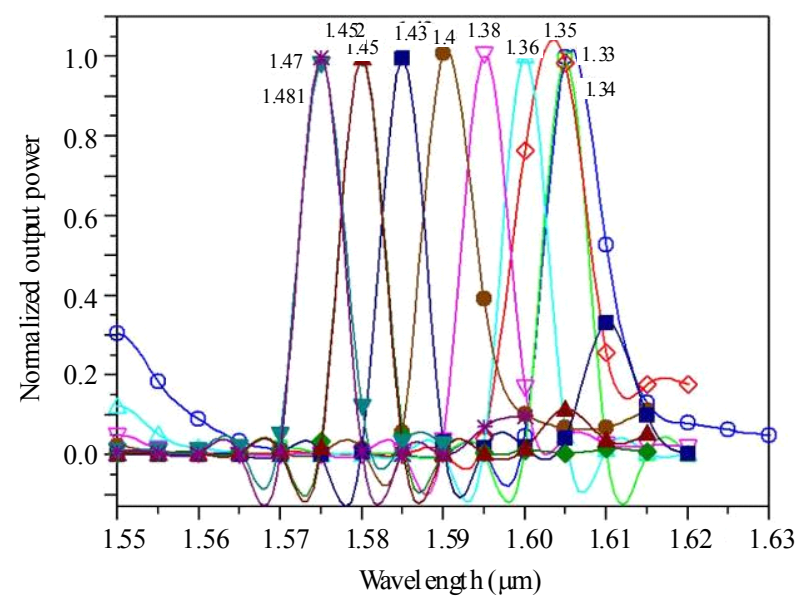

Fig. 6 Normalized output transmission spectra for normal range of blood components in blood.

The blood components with corresponding refractive index, measured value of resonant wavelength, $Q$ factor, and output efficiency are presented in Table 2. The change in the normalized transmission output power levels and equivalent resonant wavelength for every blood component have been shown experimentally, and thus each spectrum will act as a signature of the corresponding blood constituent for the designed sensor.

The design of biosensor using photonic crystal is one of the new areas for medical applications. The accuracy of the proposed model through simulation is about $97 \%$ which is sufficient for real-time applications. However, it is essential to account the fabrication tolerance of the proposed biosensor. The fabrication tolerance of the photonic crystal based 
device is $5 \%$ as already reported. In recent years, there are several methods, namely, optical lithography, direct ultraviolet (UV) laser writing, electron beam lithography, focused ion beam lithography, holographic lithography, and so on, are reported to enhance the tolerance level of photonic crystal based optical devices [44].

Table 2 Input refractive index, resonant wavelength, quality factor, and output efficiency for different blood components in blood.

\begin{tabular}{ccccc}
\hline $\begin{array}{c}\text { Name of blood } \\
\text { components }\end{array}$ & $\begin{array}{c}\text { Refractive } \\
\text { index }\end{array}$ & $\begin{array}{c}\text { Resonant } \\
\text { wavelength } \\
\text { (nm) }\end{array}$ & $Q$ factor & $\begin{array}{c}\text { Output } \\
\text { efficiency (\%) }\end{array}$ \\
\hline $\begin{array}{c}\text { Urethame } \\
\text { Dimethacrylate }\end{array}$ & 1.481 & 1575 & 262 & 98 \\
Bovine Serum & 1.470 & 1576 & 262 & 99 \\
Albumin & 1.452 & 1580 & 263 & 99 \\
Polyacrylamide & 1.450 & 1580 & 263 & 99 \\
Biotin-Streptavidin & 1.430 & 1585 & 264 & 99 \\
Sylgard184 & 1.400 & 1590 & 227 & 100 \\
Glucose & 1.380 & 1595 & 265 & 100 \\
(40 gm/100 ml) & 1.360 & 1600 & 266 & 99 \\
Hemoglobin & 1.350 & 1604 & 160 & 105 \\
Ethanol & 1.340 & 1605 & 267 & 98 \\
Blood Plasma & 1.330 & 1607 & 178 & 99 \\
Cypton & & & & \\
Water & & & & \\
\hline
\end{tabular}

Different blood components and their normal values of functional characteristics are reported in Table 2. If any patient wants to check his/her body through blood test, the minimum amount of sample will be taken from the patient. Then, the functional characteristics will be evaluated and compared with that listed in Table 2. Finally, the actual disease will be identified with less time.

The refractive indexes of the blood components are varied based on its chemical, physical, and biological properties. From Fig. 7, it is investigated that the resonant wavelength of the sensor is shifted into a higher wavelength region when the refractive index of the blood constituent is high. With an increase in the refractive index, the effective dielectric strength of the sensor increases which obviously shifts the resonant wavelength to a higher wavelength region. The functional parameters of the proposed sensor are compared with the reported ones, and the results are listed in Table 3.

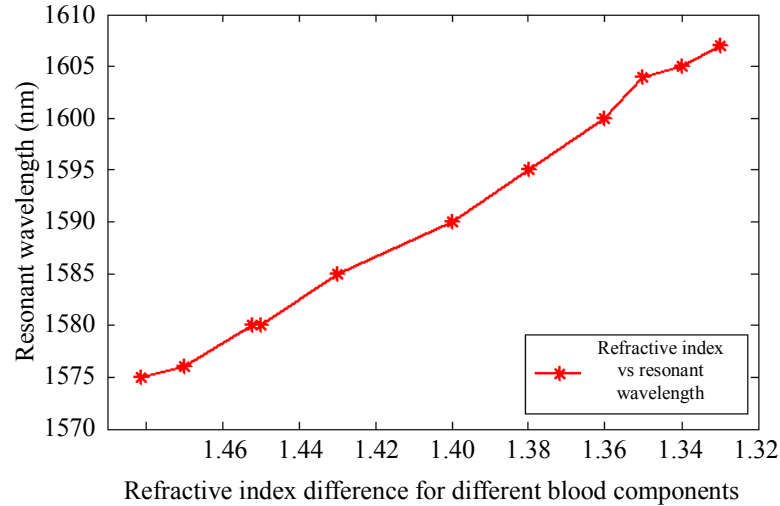

Fig. 7 Refractive index versus resonant wavelength.

Table 3 Comparison of quality factor, sensitivity, detection limit and sensing parameters of the proposed sensor with reported sensors.

\begin{tabular}{ccccc}
\hline Reference & $\begin{array}{c}\text { Quality } \\
\text { factor }\end{array}$ & $\begin{array}{c}\text { Sensitivity } \\
(\mathrm{nm} / \mathrm{RIU})\end{array}$ & $\begin{array}{c}\text { Detection limit } \\
\left(\mathrm{RIU}^{-1}\right)\end{array}$ & $\begin{array}{c}\text { Sensing parameters } \\
\text { /RI range }\end{array}$ \\
\hline$[45]$ & 1727 & $* * *$ & $* * *$ & Temperature \\
{$[46]$} & $* * *$ & $* * *$ & $* * *$ & Temperature \\
{$[47]$} & 5522 & $* * *$ & $* * *$ & Force \\
{$[48]$} & 1737 & $* * *$ & $* * *$ & Force and pressure \\
{$[49]$} & 16000 & $* * *$ & $* * *$ & Force \\
{$[50]$} & 1750 & 4.125 & $* * *$ & $1.33-1.51$ \\
{$[51]$} & 35517 & 330 & $1.24 \times 10^{-5}$ & $\begin{array}{c}\text { Deuterium water and } \\
\text { glycerol solution }\end{array}$ \\
{$[52]$} & 2700 & $* * *$ & $* * *$ & $1.33-1.48$ \\
{$[53]$} & $* * *$ & 260 & 0.001 & Refractive index \\
{$[54]$} & $* * *$ & $84 \mathrm{pm} / \mathrm{C}$ & 0.001 & Temperature \\
{$[55]$} & $1.15 \times 105$ & 462 & $3.03 \times 10^{-6}$ & Glucose concentration \\
This work & 262 & $* * *$ & 0.002 & Blood components \\
\hline
\end{tabular}

Table 3 lists the comparison of various reported PCRR based structures. From the table, it is noted that these structures are used to sense the physical, chemical, and biological parameters. Moreover, circular, rhombic, and hexagonal structure based ring resonators are highly attractive for different sensing applications and also provide better results. A high transmission efficiency of $100 \%$ is achieved by circular ring resonator, however, quality factor and refractive index sensitivity are very low which are overcome by rhombic ring resonator as providing a high refractive sensitivity of $1000 \mathrm{~nm} / \mathrm{RIU}$ and 100\% transmission efficiency. These issues are mitigated by the hexagonal ring resonator which provides a high quality factor of 35517 , and the low detection limit is $1.24 \times 10^{-5}$ with good sensitivity. All the above, the proposed 
PCRR based biosensor for detecting blood components will meet the current demands in medical applications.

\section{Conclusions}

The two dimensional photonic crystal based biosensor is proposed and designed, and its sensing characteristics are analyzed. The sensor is designed by using two dimensional photonic crystals with the cubic lattice of circular rod surrounded by air. The sensor is operated in the wavelength range from $1570 \mathrm{~nm}$ to $1610 \mathrm{~nm}$, which is used for analyzing the resonance wavelength, $Q$ factor, and output power of the sensor. Since the blood components have some specific ranges, if the level increases or decreases, it will create so many problems such as heart attack, hepatitis B and C, anemia, and diabetes, which are known as the hematological disorder. By using the designed sensor, these problems can be detected early and on time thus getting cured possibly. Hence, this work will be highly desirable for medical applications.

Open Access This article is distributed under the terms of the Creative Commons Attribution 4.0 International License (http://creativecommons.org/licenses/by/4.0/), which permits unrestricted use, distribution, and reproduction in any medium, provided you give appropriate credit to the original author(s) and the source, provide a link to the Creative Commons license, and indicate if changes were made.

\section{References}

[1] J. D. Joannopoulos, S. G. Johnson, J. N. Winn, and R. D. Meade, Photonic crystals molding the flow of light. NJ, USA: Princeton University Press Princeton, 2008: 1-304.

[2] F. L. Hsiao and C. Lee, "Novel biosensor based on photonic crystal nano-ring resonator," Procedia Chemistry, 2009, 1(1): 417-420.

[3] P. Sharma and P. Sharan, "Design of photonic crystal based ring resonator for detection of different blood constituents," Optics Communications, 2015, 348: 19-23.

[4] P. Sharma and P. Sharan, "Photonic crystal based ring resonator sensor for detection of glucose concentration for biomedical application," International Journal of Emerging Technology and Advanced Engineering, 2014, 4(30): 702-706.
[5] M. Lee and P. M. Fauchet, "Two-dimensional silicon photonic crystal based bio sensing platform for protein detection," Optics Express, 2007, 15(8): 4530-4535.

[6] Roggan, M. Friebel, K. Dörschel, A. Hahn, and G. Müller, "Optical properties of circulating human blood in the wavelength range 400-2500 nm," Journal of Biomedical Optics, 1994, 4(1): 36-46.

[7] M. Friebel and M. Meinke, "Determination of the complex refractive index of highly concentrated hemoglobin solutions using transmittance and reflectance measurements," Journal of Biomedical Optics, 2005, 10(6): 064019-1-064019-5.

[8] A. Roggan, M. Friebel, K. Dörschel, A. Hahn, and G. Müller, "Optical properties of circulating human blood in the wavelength range 400-2500 nm," Journal of Biomedical Optics, 1999, 1(1): 36-46.

[9] L. G. Lindberg and P. A. Öberg, "Optical properties of blood in motion," Optical Engineering, 1993, 32(2): 253-257.

[10] A. M. K. Enejder, J. Swartling, P. Aruna, and S. A. Engels, "Influence of cell shape and aggregate formation on the optical properties of flowing whole blood," Applied Optics, 2003, 42(7): 1384-1394.

[11] V. S. Lee and L. Tarassenko, "Absorption and multiple scattering by suspensions of aligned red blood cells," Journal of the Optical Society of America, 1993, 8(7): 1135-1141.

[12] R. Bayer, S. Çaglayan, and B. Günther, "Discrimination between orientation and elongation of RBC in laminar flow by means of laser diffraction," SPIE, 1993, 2136: 105-113.

[13] X. Fan, I. M. White, S. I. Shopova, H. Zhu, J. D. Suter, and Y. Sun, "Sensitive optical biosensors for unlabeled targets: a review," Analytica Chimica Acta, 2008, 6(20): 8-26.

[14] R. W. Boyd and J. E. Heebner, "Sensitive disk resonator photonic biosensor," Applied Optics, 2001, 18(31): 15742-5747.

[15] I. M. White and X. Fan, "On the performance quantification of resonant Refractive index sensors," Optics Express, 2008, 16(2): 1020-1028.

[16] C. Kang, C. Phare, and S. M. Weiss, "Photonic crystal defects with increased surface area for improved refractive index sensing," in Proceeding of Conference on Laser and Electro Optics and Quantum Electronics and laser Science, San Jose, California, United States, 2010, pp. 1-2.

[17] E. Yablonovitch, "Inhibited spontaneous emission in solid-state physics and electronics," Physical Review Letters, 1987, 58(23): 2059-2062.

[18] S. John, "Strong localization of photons in certain disordered dielectric super lattices," Physical Review Letters, 1987, 58(20): 2486-2489.

[19] C. Lee, J. Thillaigovindan, and R. Radhakrishnan: "Design and modeling of nano mechanical sensors using silicon 2-D photonic crystals," Journal of 
Light Wave Technology, 2008, 26(7): 839-846.

[20] S. Robinson and R. Nakkeeran, "Photonic crystal ring resonator-based add drop filters: a review," SPIE, 2013, 52(6): 1-15.

[21] V. D. Kuma, "Analysis and simulations of photonic crystal components for optical communication," Ph.D. dissertation, Helsinki University of Technology, Helsinki, Finland, 2003.

[22] Y. Liu and H. W. M. Salemink, "Photonic crystal-based all-optical on-chip sensor," Optics Express, 2012, 20(18): 19912-19920.

[23] K. V. Shanthi and S. Robinson, "Two-dimensional photonic crystal based sensor for pressure sensing," Photonic Sensors, 2014, 4(3): 248-253.

[24] M. Radhouene, M. K. Chhipa, M. Najjar, S. Robinson, and B. Suthar, "Novel design of ring resonator based temperature sensor using photonics technology," Photonic Sensors, 2017, 7(4): 311-316.

[25] T. Zouache, A. Hocini, A. Harhouz, and R. Mokhtari, "Design of pressure sensor based on two-dimensional photonic crystal," Acta Physica Polonica, 2017, 131(1): 68-70.

[26] S. Robinson and R. Nakkeeran, "PC based optical salinity sensor for different temperatures," Photonic Sensors, 2012, 2(2): 187-192.

[27] W. C. L. Hopman, P. Pottier, D. Yudistira, J. V. Lith, P. V. Lambeck, R. M. D. L. Rue, et al., "Quasi-one-dimensional photonic crystal as a compact building block for refract metric optical sensors," IEEE Journal of Selected Topics in Quantum Electron, 2005, 11(1): 11-16.

[28] V. S. Lee and L. Tarassenko, "Absorption and multiple scattering by suspensions of aligned red blood cells," Journal of the Optical Society of America, 1991, 8(7): 1135-1141.

[29] R. Bayer, S. Çaglayan, and B. Günther, "Discrimination between orientation and elongation of RBC in laminar flow by means of laser diffraction," SPIE, 1994, 2136: 105-113.

[30] A. M. K. Enejder, J. Swartling, P. Aruna, and S. A. Engels, "Influence of cell shape and aggregate formation on the optical properties of flowing whole blood," Applied. Optics, 2003, 42(7): 1384-1394.

[31] L. G. Lindberg and P. A. Öberg, "Optical properties of blood in motion," Optical Engineering, 1993, 32(2): 253-257.

[32] P. Sharma and P. Sharan, "An analysis and design of photonic crystal based bio chip for detection of glycosuria," IEEE Sensor Journal, 2016, 15(10): 5569-5575.

[33] T. Dharchana, A. Sivanantharaja, and S. Selvendran, "Design of pressure sensor using 2D photonic crystal," Advances in Natural and Applied Sciences, 2017, 11(7): 26-30.

[34] V. Sharma and V. L. Kalyani, "Design two dimensional nanocavity photonic crystal biosensor detection in malaria," International Journal of
Emerging Research in Management and Technology, 2017, 6(6): 16-20.

[35] S. Robinson and R. Nakkeeran, "PCRR based bandpass filter for $\mathrm{C}$ and $\mathrm{L}+\mathrm{U}$ bands of ITU-T G.694.2 CWDM systems," Optics and Photonics Journal, 2011, 1(3): 142-149.

[36] G. Pelosi, R. Coccioli, and S. Selleri, Quick finite elements for electromagnetic waves. Boston, London, England: Artech House, 1997: 1-289.

[37] A. Taflove and S. C. Hagness, Computational electrodynamics: the finite-difference time-domain method. Boston, London, England: Artech House, 2005: 1-1038.

[38] S. G. Johnson and J. D. Joannopoulos, "Block-iterative frequency domain methods for Maxwell's equation in a plane wave basis," Optics Express, 2000, 11(3): 173-190.

[39] S. Guo and S. Alloin, "Simple plane wave implementation for photonic crystal calculation," Optics Express, 2003, 11(2): 167-175.

[40] R. Scarmozzino, A. Gopinath, R. Pregla, and S. Helfert, "Numerical techniques for modeling guided-wave photonic devices," IEEE Journal of Selected Topics in Quantum Electronics, 2000, 6(1): 150-162.

[41] M. Loncar, J. Vuckovic, and A. Scherer, "Methods for controlling positions of guided modes of photonic-crystal waveguides," Optical Society of America, 2001, 18(9): 1362-1368.

[42] S. P. Guo, S. Albin, and A. Scherer, "Numerical techniques for excitation and analysis of defect modes in photonic crystals," Optical Society of America, 2003, 11(9): 1080-1089.

[43] Y. Akahane, T. Asano, B. S. Song, and S. Noda, "High- $Q$ photonic nano cavity in a two dimensional photonic crystal," Nature, 2003, 425: 944-947.

[44] F. DellOlio, C. Ciminelli, D. Conteduca, and M. N. Armenise, "Effect of fabrication tolerances on the performance of two dimensional polymer photonic crystal channel drop filter: a theoretical investigation based on the finite element method," Optical Engineering, 2013, 52(9): 097104-1-097104-7.

[45] M. Radhouene, M. K. Chhipa, M. Najjar, S. Robinson, and B. Suthar, "Novel design of ring resonator based temperature sensor using photonics technology," Photonic Sensors, 2017, 7(4): 1-6.

[46] C. S. Mallika, I. Bahaddur, P. C. Srikanth, and P. Sharan, "Photonic crystal ring resonator structure for temperature measurement," Optik, 2015, 126(20): 2252-2255.

[47] T. T. Mai, F. L. Hsiao, C. K. Lee, W. F. Xiang, C. C. Chen, and W. K. Choi, "Optimization and comparison of photonic crystal resonators for silicon micro cantilever sensors," Sensors and Actuators A: Physical, 2010, 165: 16-25.

[48] B. Li and C. K. Lee, "NEMS diaphragm sensors 
integrated with triple-nano-ring resonator," Sensors and Actuators A: Physical, 2011, 172: 61-68.

[49] T. Sreenivasulu, V. Rao, T. Badrinarayana, G. K. Hegde, and T. Srinivas, "Photonic crystal ring resonator based force sensor: design and analysis," Optik, 2018, 155: 111-120.

[50] S. Olyaee and A. M. Bahabady, "Two-curve-shaped biosensor using photonic crystal nano-ring resonators," Journal of Nanostructures, 2014, 4: 303-308.

[51] L. J. Huang, H. P. Tian, D. Q. Yang, J. Zhou, Q. Liu, P. Zhang, et al., "Optimization of figure of merit in label-free biochemical sensors by designing a ring defect coupled resonator," Optics Communication, 2014, 332: 42-49.

[52] S. Olyaee and A. M. Bahabady, "Designing a novel photonic crystal nano-ring resonator for biosensor application," Optical \& Quantum Electronics, 2015, 47: 1881-1888.

[53] A. Harhouz and A. Hocini, "Design of high-sensitive biosensor based on cavity- waveguides coupling in 2D photonic crystal," Journal of Electromagnic Wave Applications, 2015, 29(5): 659-667.

[54] A. Hocini and A. Harhouz, "Modeling and analysis of the temperature sensitivity in two dimensional photonic crystal microcavity," Journal of Nanophotonics, 2016, 10(1): 016007-016010.

[55] S. Arafa, M. Bouchemat, T. Bouchemat, A. Benmerkhi, and A. Hocini, "Infiltrated photonic crystal cavity as a highly sensitive platform for glucose concentration detection," Optics Communication, 2017, 384: 93-100. 